\title{
LER, CONTAR E ESCREVER: EDUCAÇÃO E LIVROS NO RIO DE JANEIRO JOANINO (1808-1821) ${ }^{1}$
}

\author{
The three Rs: books and schooling \\ in Rio de Janeiro (1808-1821)
}

Lucia Maria Bastos Pereira das Neves*

\begin{abstract}
RESUMO
No contexto da vinda da família real portuguesa para o Rio de Janeiro, em 1808, era prioridade a criação de uma sociedade ilustrada, que diferisse daquela predominantemente oral e iletrada que habitava as terras distantes da colônia, agora sede do Império. Sabe-se hoje com segurança que, como resultado, a instalação de um aparelho administrativo da Coroa na América permitiu uma certa modernização do Rio de Janeiro de acordo com padrões europeus. A proposta desse artigo é então a de analisar as políticas do governo de D. João, que, por meio das licenças para a criação de colégios e poucas escolas superiores, bem como dos livros que saíam da Impressão Régia, contribuíram para a difusão do uso do escrito e do conhecimento em geral. De um lado, havia a necessidade de instruir os filhos das elites que vinham do Reino e os que aqui haviam nascido, a fim de formar quadros destinados à administração; de outro, as publicações de livros, impressos localmente ou no exterior, capazes de contribuir para tal objetivo. Dessa forma, ideias novas e notícias passaram a circular de maneira bem mais intensa, em geral transmitidas pela força do impresso, ainda que difundidas, no mais das vezes, por meio oral. Logo, no Brasil das primeiras décadas do oitocentos, os livros e o ensino possibilitaram o surgimento de novas formas de sociabilidade e de um espaço público de poder, em que mais tarde puderam ser questionados alguns dos valores tradicionais, como o governo absoluto e a expressão retórica.
\end{abstract}

Palavras-chave: circulação de livros; instrução; arte da escrita.

" Professora Titular de História Moderna da Universidade do Estado do Rio de Janeiro.

1 Pesquisa financiada pelo CNPq (bolsista de Produtividade 1A), pela FAPERJ (Cientista do Nosso Estado) e pelo Prociência da UERJ. 


\begin{abstract}
In 1808, when Portugal's royal family moved to Rio de Janeiro, one priority was the creation of a enlightened society, different from the mostly oral and uncultured one which had inhabited the far away colony, now head of the Empire. It is well known that, as a result, the need to build new administrative devices in America allowed for some kind of modernization of the city according to Europeans standards. This paper focus then on the policies of the Prince Regent's government aspiring to spread literacy skills and knowledge in general, including books that came out from the Royal Press, the very few institutions of higher learning that were erected and consents granted to open private schools. On the one hand, it was necessary to teach the elite children who had left Europe and those whose parents already lived in America in order to form the future administrative staff of the empire; were they imported or locally printed, on the other hand, there had to be books available to attain that goal. In this way, news and ideas began to circulate much more widely, usually carried by the printed matter, but more often disseminated by oral means. Therefore, in the first decades of the $19^{\text {th }}$ century, books and schooling forwarded new forms of sociability and the outline of a power public sphere, in which traditional values - like absolute monarchy and rhetorical expression - could later be called into question.
\end{abstract}

Keywords: circulation of books; schooling; literacy.

$$
* * *
$$

As nações e governos de mais luzes sempre exerceram real supremacia, ou decisiva preponderância e influência, sobre os outros Estados menos ilustrados.

José da Silva Lisboa ${ }^{2}$

Na visão de Silva Lisboa, ao relacionar cultura e política entre as várias nações, um Estado era tanto mais poderoso quanto mais ilustrado fosse, estabelecendo uma ligação direta entre as luzes, a instrução e mesmo a ordem da política interna. No Rio de Janeiro, sede do governo do Brasil desde 1763, entretanto, atividades comuns de uma sociedade letrada, necessárias para

2 LISBOA, José da Silva. Observações sobre a prosperidade do Estado pelos liberaes princípios da nova legislação do Brazil. Rio de Janeiro: Impressão Régia, 1810. p. 72. 
o progresso daquela colônia - ler, contar e escrever - encontravam-se em parte ausentes. Apesar dos esforços de diversos vice-reis para impulsionar a cidade, o ensino ficava, em sua essência, reduzido às aulas régias, em número ainda bastante restrito. O Almanaque do Rio de Janeiro para o ano de 1794 indicava apenas seis professores para as aulas régias de filosofia, retórica, grego, gramática e de ler, contar e escrever. ${ }^{3}$ Muito pouco para a sede da América portuguesa.

Novos tempos, porém, fizeram-se sentir após 1808, com a instalação da Corte no Rio de Janeiro. Era o tempo do rei, que proclamava sua intenção de criar "um novo império" naquela cidade. ${ }^{4}$ Para tal objetivo, era necessário promover transformações que fizessem da simples cidade colonial a nova sede do Império português. Introduziam-se novas instituições de governo, mudanças no comércio com sua abertura às nações amigas, ou seja, a Inglaterra, embelezamento da própria cidade, por meio de construção de habitações, melhoria no abastecimento de água e alimentos, maior limpeza e higiene e iluminação das ruas. Além disso, uma inédita concepção de sociabilidades, copiada do modelo europeu, sobretudo francês, conduziu ao aumento de festas e saraus da elite. ${ }^{5}$ Buscava-se, por fim, a instalação de uma sociedade de corte, cujos hábitos e exigências tendiam a difundir-se pela população, contribuindo para aquilo que Norbert Elias denominou de processo civilizador ${ }^{6}$ e despertando a antiga colônia para um processo de modernização.

Se a presença da Corte possibilitou alterar o estilo de vida no Brasil, tanto no tocante ao mundo da política quanto ao próprio comportamento da sociedade, tornava-se também imprescindível que mudanças fossem introduzidas na educação e, por conseguinte, na cultura escrita. ${ }^{7}$ Aspecto fundamental foi a criação da Impressão Régia (13 de maio de 1808), cuja

3 Almanaque da Cidade do Rio de Janeiro para o ano de 1794. In: Anais da Biblioteca Nacional do Rio de Janeiro. Rio de Janeiro: Serviço Gráfico do Ministério da Educação, 1940. p. 341-342.

4 MATTOS, Ilmar R. de. Rio de Janeiro. In: VAINFAS, Ronaldo; NEVES, Lucia Bastos P. das. Dicionário do Brasil Joanino, 1808-1821. Rio de Janeiro: Objetiva, 2008. p. 393-397.

5 Para a vida quotidiana desse período, cf. SILVA, Maria Beatriz Nizza da. Vida privada e quotidiana no Brasil: na época de D. Maria I e D. João VI. Lisboa: Estampa, 1993

6 ELIAS, Norbert. O processo civilizacional. v. 1. Lisboa: Dom Quixote, 1989.

7 Para uma análise sobre a cultura escrita do Brasil no tempo colonial, ver GONZALEZ SÁNCHEZ, Carlos Alberto. La cultura escrita en el Mundo Atlántico colonial: Brasil y América del norte. Claves historiográficas, retos y perspectivas. Revista de Indias, Madrid, v. LXXVIII, n. 259, p. 633-662, 2013. O autor propõe ainda, em seu artigo, a necessidade de se fazer um estudo comum da história das Américas. 
principal função era divulgar as medidas do governo instalado no Rio de Janeiro, como atos legislativos e papéis diplomáticos. Na ausência de outra tipografia, ainda se previa a impressão de todas as obras, sobretudo aquelas que ajudassem a divulgar a imagem da própria monarquia. Devia também publicar edições úteis que difundissem "as luzes pelo povo". ${ }^{8}$ Tal situação só foi alterada com a criação das primeiras tipografias particulares: em 1811, na Bahia, pelo comerciante português Manoel Antonio da Silva Serva, e no Rio de Janeiro, em 1821.

Dessa forma, o mercado livreiro, que apresentava proporções restritas, atendendo demandas bastante específicas, voltadas para obras destinadas às áreas profissionais, ampliou-se. Para além dos livros publicados na antiga sede do Império português, despachados para localidades diversas como Rio de Janeiro, Bahia, Maranhão, Pernambuco e Pará, contava-se agora com aqueles impressos na nova Corte.

A transmissão de valores, de normas e de conhecimentos tornava-se, portanto, importante naquele momento de constituição de uma sociedade letrada, devendo ser realizada por meio de novas formas de educação. Confirmava-se, na visão de época, a afirmativa de Silva Lisboa: "as luzes das ciências, dirigindo a todas as artes e indústrias [...] não só dão o esplendor, mas também o sustento dos impérios".

\section{Dos Colégios e das Academias}

Distribuer un capital culturel, et par là reproduire les rôles sociaux dominantes, telle est la tâche du collège.

R. Chartier, M. M. Compère e D. Julia ${ }^{10}$

A nova situação vivenciada pelo Rio de Janeiro a partir de 1808 possibilitou o estabelecimento de colégios tanto para meninas quanto

8 LISBOA, José da Silva. Observações sobre a prosperidade do Estado pelos liberaes... p.

77.

9 Ibidem, p. 72.

10 CHARTIER, R.; COMPÈRE, M. M.; JULIA, D. L'Éducation en France du XVI $I^{e}$ au XVIII siècle. Paris: SEDES, 1976. p. 175. 
para meninos e a continuidade dos estudos públicos que multiplicavam as oportunidades para os variados segmentos da sociedade. Regra geral, fora as aulas régias, a instrução desde as primeiras letras até os estudos mais adiantados ficava a cargo de particulares, sendo muitas vezes portugueses já habituados ao ensino em Portugal ou eclesiásticos que não estavam colados a uma paróquia. Além disso, Rodrigo de Sousa Coutinho, ministro ilustrado de D. João, concebia um plano harmonioso para a Instrução Pública em relação à Marinha e ao Exército, dando também início aos estudos destinados ao comércio e à arte de curar. Na época, era constante a ideia de que Sua Alteza Real "nada poupa, para que possa contribuir ao melhoramento da educação dos seus fiéis Vassalos"."

Por meio dos anúncios da Gazeta do Rio de Janeiro e de documentos da Mesa do Desembargo do Paço, é possível acompanhar a trajetória de um professor de latim e português, Joaquim Manuel de Faria, chegado ao Brasil depois da vinda da Corte. Em anúncio de que não constava o nome do colégio ou de seu diretor, informava-se que um professor de gramática portuguesa e latina, vindo há pouco de Lisboa e situado no Beco dos Quartéis, ensinava "com a perfeição possível" a gramática portuguesa e sua ortografia; "ciência de contar", "gramática latina; filosofia racional e moral, em diferentes horas do dia". Em certos dias da semana, havia aulas de política e civilidade cristã. Curiosa era a informação que, a partir das 7 horas da noite, havia aulas exclusivamente para caixeiros, que, "em razão de suas ocupações", não podiam concorrer de dia. ${ }^{12}$

Em outubro de 1809, com autorização e privilégio de Sua Alteza Real, Joaquim Manoel de Faria transferiu-se do Beco dos Quartéis para a Rua dos Pescadores, por ser esta uma melhor rua, com casas mais adequadas. ${ }^{13}$ No ano seguinte, no entanto, já abre um colégio de educação com a aprovação do soberano, informando que, de acordo com o plano apresentado ao príncipe regente, inaugurava uma aula de francês, cujo mestre era o padre Manoel Fernandes Leal, conhecido por sua "vasta erudição, como

11 Gazeta do Rio de Janeiro, n. 111, 4 de outubro de 1809.

12 Gazeta do Rio de Janeiro, n. 81, 21 de junho de 1809. O anúncio afirmava que "na freguesia de Santa Rita, Beco dos Quartéis, n. ${ }^{\circ} 5$, assiste um professor de gramática portuguesa e latina, vindo há pouco tempo de Lisboa".

13 Gazeta do Rio de Janeiro, n. 114, 14 de outubro de 1809. Para o plano de educação de sua escola, ver Arquivo Nacional. Mesa do Desembargo do Paço. Caixa 148. 
rara virtude". ${ }^{14}$ No final de 1811 , em reconhecimento por seus serviços na educação da mocidade, ele alcançava a mercê do Príncipe Regente de isentá-lo, assim como seus professores e alunos, de "todo e qualquer recrutamento", permitindo ainda que eles trouxessem no peito com "fita amarela o Emblema da Sabedoria aberto em medalha de prata". Nesse mesmo despacho, informava-se que o colégio abria uma nova aula - a de desenho. ${ }^{15}$

A ascensão de Manoel de Faria continuava. Por novo anúncio em 1812, intitulava-se diretor "do novo colégio de nobres nesta capital", que, além das aulas de português, latim, francês, princípios de matemática e desenho, abria mais uma de inglês. ${ }^{16}$ Qual era esse colégio? A resposta pode ser encontrada tanto em um pedido de licença à Mesa do Desembargo do Paço para imprimir "planos do novo Colégio" com "mapas de aulas" quanto em um novo aviso da Gazeta. O mapa das Aulas, Mestres e Alunos do Colégio de Minerva, datado de janeiro de 1812, traz informações preciosas para se obter uma visão do que fora a instituição. As aulas de português, aritmética e latim eram ministradas por Joaquim Manoel de Faria, que também era proprietário e diretor do estabelecimento. Talvez, por essas múltiplas funções, as cadeiras tinham dois professores substitutos: Manoel Pereira e Paulo José de Souza Pereira, sendo este último ainda professor de língua inglesa. O padre Manoel Fernandes Leal ensinava francês; Joaquim Pedro Gamboa, desenho.

Naquela ocasião, achavam-se matriculados 90 alunos, entre as idades de 7 e 17 anos. Eram provenientes de diversos lugares: do Rio de Janeiro, 47 estudantes, ou seja, quase a metade dos alunos (52,2\% do total); do Reino, 19; de Lisboa, 15; da Bahia e de Santa Catarina, 2 alunos de cada; de Campos e Minas Gerais, um aluno de cada, e a mesma quantidade de Angola, Moçambique e Inglaterra. Entre os alunos, alguns sobrenomes conhecidos, filhos de negociantes de grosso trato e ligados ao comércio de escravos, como Elias Antonio Lopes e Gomes Barroso; filhos de homens ligados à administração, como José Maria Targini e da família Picanço - José Correia Picanço, médico da família real; filhos de nobres, como o Conde de Belmonte, que mantinha relações muito próximas com a Casa de Bragança. Verifica-se, assim, que era um colégio destinado tanto aos filhos das elites

14 Gazeta do Rio de Janeiro, n. 59, 25 de julho de 1810.

15 Gazeta do Rio de Janeiro, n. 100, 14 de dezembro de 1811.

16 Gazeta do Rio de Janeiro, n. 5, 15 de janeiro de 1812. 
do Rio de Janeiro quanto àqueles que, por meio de ascensão social, procuravam integrar as altas camadas da nova sociedade, embora não deixasse de incluir também os que vieram para cá com a Família Real.

Ainda curiosa é a identificação dos alunos com uma avaliação sobre seus costumes, talentos e aplicação. A avaliação apresentava diversas categorias: ótimo, bom, suficiente, mau e péssimo. O estudante de Minas José Maria Camizão, com oito anos de idade, obtinha péssimo tanto em talentos quanto em aplicação. Já o filho de Correia Picanço, também com oito anos, alcançava ótimo em todas as avaliações. ${ }^{17}$

Um ano depois, o mesmo diretor anunciava na Gazeta a substituição de seu professor de francês, que recebera um benefício real. Monsieur Lalain, "sacerdote francês de nação", emigrado no tempo da revolução e respeitável pelos seus "vastos conhecimentos, retidão de costumes, pureza da religião e avançada idade", era o novo professor. Este, provavelmente, possuía uma maior pureza na pronúncia da língua que ensinava, sabendo também português, "circunstância muito atendível para este fim". ${ }^{18}$ Dessa maneira, diversificando seu ensino entre nobres e caixeiros, Joaquim Manoel de Faria prestou relevantes serviços à instrução daquela época.

Ainda nesta mesma linha de ação, o professor de primeiras letras Jordão Reinaldo, vindo de Lisboa com sua família, em julho de 1811, e desejando continuar a ser o educador de seus filhos, resolveu se encarregar da direção de um Colégio, onde ia ensinar "tudo que é preciso para ser um hábil Negociante e um útil Cidadão". ${ }^{19}$ Anos mais tarde, outro anúncio informava que Jordão Reinaldo mudava seu endereço, mas continuava "a fazer o possível para bem servir o respeitável público na instrução da mocidade" que lhe era confiada. Seus alunos eram instruídos em ler, escrever e falar gramaticalmente as línguas portuguesa, francesa e inglesa, além de aritmética, álgebra, geografia natural. Também dava lições de escrita e aritmética, à noite, das sete às nove horas, demonstrando uma preocupação com o ensino noturno, voltado para adultos que, em função de suas ativi-

17 Arquivo Nacional. Mesa do Desembargo do Paço. Licenças, caixa 170, pac. 1, doc. 8, janeiro de 1812 .

18 Gazeta do Rio de Janeiro, n. 28, 7 de abril de 1813. Maria Beatriz Nizza da Silva, em $A$ Gazeta do Rio de Janeiro (1808-1822), Cultura e sociedade. Rio de Janeiro, EdUERJ, 2007, indica alguns anúncios de Manoel de Faria (p. 107-109), mas não o relaciona como diretor do Colégio de Minerva, provavelmente, por não ter tido acesso ao documento da Mesa do Desembargo do Paço.

19 Gazeta do Rio de Janeiro, n. 62, 3 de agosto de 1811. 
dades, não o podiam fazer ao longo do dia. ${ }^{20}$ Da mesma forma, Antonio Maria Baker, professor de escrita, aritmética e gramática portuguesa, além de ensinar em casas particulares, propunha-se "das Ave-Marias em diante" a ensinar em sua casa aquelas pessoas que desejassem aperfeiçoar-se e não o faziam "por causa das suas ocupações diárias". ${ }^{21}$

A preocupação com as aulas noturnas era frequente nos anúncios: o clérigo Guilherme Paulo Tillbury (1784-1863), que possui singular e longa trajetória, também oferecia serviços para estudantes à noite. Era natural de Londres, proveniente do Colégio Católico daquela cidade, e dava aulas de inglês, na rua do Rosário. Em seu primeiro anúncio, datado de 1817, informava receber 20 alunos. As aulas eram ainda de francês, geografia e belas letras, pela manhã e à tarde: pessoas empregadas de dia tinham aulas de francês e inglês, à noite, de seis até as oito. ${ }^{22}$ Em outro aviso, fazia "ciente ao público" as horas de suas aulas, com aprovação da Mesa do Desembargo do Paço: pela manhã, aulas de francês, geografia e prática nos globos e inglês com duração de duas horas cada a partir das 8 horas. Nas segundas, quartas e sextas, à tarde, havia aula de língua portuguesa para estrangeiros. De noite, aulas de francês e inglês: a primeira, na segunda, quarta e sexta e a outra, na terça, quinta e sábado, todas de 7 h até as $9 \mathrm{~h}$. O preço de cada aula era de $4 \$ 000$ por mês e se o aluno frequentasse duas ou mais, $6 \$ 400 .{ }^{23}$ Outros avisos se sucederam até 1820 . No entanto, padre Tillbury permaneceu no Rio de Janeiro, dedicando-se ao ensino da língua inglesa, escrevendo inclusive uma gramática em 1827 - Arte ingleza offerecida ao illustrissimo Senhor Visconde de Cayru -, publicada pela Tipografia Nacional. Ainda em 1858, fez uma petição à Câmara dos Deputados para que fossem pagos ordenados quando esteve fora do exercício da cadeira pública de língua inglesa na Corte, desde 1831 até 1848 . Afirmava que havia sido "esbulhado" da propriedade de sua cadeira. Em 1860, a Câmara aprovou o pedido do professor. Dessa forma, padre Guilherme Paulo Tillbury teve longa atuação no ensino e na instrução no Rio de Janeiro. ${ }^{24}$

20 Gazeta do Rio de Janeiro, n. 101, 19 de dezembro de 1818. O mesmo anúncio se repetiu no n. 8 de 27 de janeiro de 1819 .

21 Gazeta do Rio de Janeiro, n. 68, 16 de agosto de 1818.

22 Gazeta do Rio de Janeiro, n. 101, 17 de dezembro de 1817; n. 76, 23 de setembro de 1818.

23 Gazeta do Rio de Janeiro, n. 102, 22 de dezembro de 1819.

24 Annaes do Parlamento Brazileiro. Sessão de 1858. T. 3, Rio de Janeiro, Typographia Imperial e Constitucional de J. Villeneuve \& C., p. 307. Annaes do Parlamento Brazileiro. Sessão de 1860. T. 1, Rio de Janeiro, Typographia Imperial e Constitucional de J. Villeneuve \& C., 1860, p. 264. 
O oferecimento de instrução específica, por meio desses cursos à noite para jovens e adultos, especialmente para os caixeiros, que se tornavam figuras fundamentais tanto no comércio a retalho quanto no de grosso trato, era, portanto, uma nova realidade. Tal questão pode justificar a atitude de alguns negociantes abastados da praça do Rio de Janeiro, como a família Carneiro Leão e Amaro Velho da Silva, entre outros, que fizeram uma oferta ao Príncipe Regente D. João em oferecer voluntariamente uma subscrição para a formação de um capital a ser empregado em ações do Banco do Brasil, cujo rendimento anual devia ser "privativa e perpetuamente aplicado para Estabelecimentos que promovam a Instrução Nacional". ${ }^{25}$

As diversas atividades que enriqueciam o mundo dos negócios na nova Corte levaram ao ensino de ações específicas no mundo profissional. Para além dos caixeiros, havia uma preocupação com o comércio, com a pilotagem para os que quisessem seguir carreira na Marinha e não pudessem frequentar as aulas da Academia Real dos Guardas-Marinhas, aprendendo as "matérias pertencentes à navegação". ${ }^{26}$ Ensinava-se também a geografia elementar "com detalhes relativos ao comércio, marinha, agricultura, arte militar" e os princípios necessários à construção de cartas ou mapas. ${ }^{27}$ Ainda, como menciona Maria Beatriz Nizza da Silva, havia um possível mercado de trabalho para quem quisesse aprender "estenografia portuguesa, ou arte de escrever com rapidez a palavra, convenção adotada em todos os idiomas". ${ }^{28}$ Dois professores franceses, M. de Reynaud e M. Bonhomme, especializados em línguas, ensinavam história e mitologia, diversificando as áreas do conhecimento. ${ }^{29}$

A novidade maior, nesse novo leque de possibilidades, era, sem dúvida, a instrução das meninas, abrindo-se aulas e colégios até mesmo para aquelas que se situavam nas camadas mais baixas da sociedade. Em 1809, há a indicação de uma professora inglesa, na rua do Ourives, com "casa de educação [de] meninas" que quisessem aprender a ler, escrever, contar e falar inglês e português, além de bordar e coser. ${ }^{30}$ Bastante conhecida era

28 SILVA, Maria Beatriz Nizza da. A Gazeta do Rio de Janeiro..., p. 111. Para o anúncio, ver Gazeta do Rio de Janeiro, n. 50, 21 de junho de 1817.

29 Jornal de Annuncios. Rio de Janeiro, n. 7, 16 de junho de 1821.

30 Gazeta do Rio de Janeiro, n. 103, 6 de setembro de 1809. 
a instituição de D. Catarina Jacob, situada na Rua da Lapa. Ensinava-se a ler, escrever, falar as línguas portuguesa e inglesa e sua gramática, como também a bordar, a costurar e o manejo da casa. O sistema era de internato, em que cada aluna devia trazer "cama completa, três toalhas de mão, um talher completo e copo de prata". Deviam pagar $18 \$ 000$ réis por mês, sendo que a "quartéis adiantados". Se as meninas aprendessem "música, dança e desenho", o pagamento era à parte. Todo o sábado, os pais deviam mandar seus criados à instituição com a roupa necessária para se fazer a substituição. Também no sábado à tarde ou véspera de dia santo podiam apanhar as alunas, desde que retornassem à escola até as 8 horas da noite do domingo ou do dia santo. ${ }^{31}$ Meses depois, novo anúncio informava que, além do internato, havia a possibilidade de aulas para se aprender lições só de dia, pagando $12 \$ 000$ réis mensais, um mês adiantado. Informava ainda que obtivera o privilégio da Princesa D. Carlota Joaquina de permitir que suas alunas pudessem trazer uma medalha com o retrato da mesma, mostrando reconhecimento por seu trabalho com a educação feminina. ${ }^{32}$

Em 1818, um curioso anúncio informava a abertura de Colégio para meninas na rua Matacavalos, onde estas aprenderiam a ler, contar, escrever, coser, com aulas também de música, canto e ensino para fazer flores. O mesmo anúncio afirmava que a casa fazia toda a qualidade de costura de homem e de senhora, lavava-se e engomava-se de pregas e lavavam-se meias de seda. Fica a indagação: esses serviços seriam feitos pelas alunas como aprendizagem? As fontes não fornecem resposta. ${ }^{33}$

Os anúncios se multiplicavam, mostrando que parecia ser um bom negócio a oportunidade do ensino feminino. Em alguns, aparecia mesmo uma novidade: instruíam-se também escravas a coser, engomar, bordar, marcar e cozinhar. ${ }^{34}$ Por tais anúncios, verifica-se que, para além de dar uma

31 Gazeta do Rio de Janeiro, n. 2, 6 de janeiro de 1813.

32 Gazeta do Rio de Janeiro, n. 27, 3 de abril de 1813. Esse estabelecimento é citado por Nizza da Silva. Gazeta do Rio de Janeiro..., p. 104 e RIBEIRO, Arilda Ines Miranda. Mulheres Educadas na Colônia. In: LOPES, Eliane Marta Teixeira; FARIA FILHO, Luciano Mendes de; VEIGA, Cynthia Greive (Orgs.). 500 anos de Educação no Brasil. 2. ed. Belo Horizonte: Autêntica, 2000. p. 79-94. Para uma ideia do valor do preço na época, pode-se informar que a Loteria do Real Teatro de São João oferecia 1.363 prêmios no valor de $12 \$ 000$ réis e que a Coleção completa de mapas intitulada Piloto Africano custava, então, $16 \$ 000$ réis.

33 Gazeta do Rio de Janeiro, n. 70, 2 de setembro de 1818.

34 Diário do Rio de Janeiro, n. 2, 3 de julho de 1821. Cf. ainda Gazeta do Rio de Janeiro, n. 28,7 de abril de 1821 e n. 55 , de 9 de julho de 1814 , em que se ensinavam a "negrinhas" e escravas. 
instrução básica às meninas, havia ainda uma preocupação com o ensino de tarefas práticas destinadas àquelas que atuavam no mercado de trabalho.

Havia ainda casa de instrução para a mocidade de "um e outro sexo". O principal objetivo era a formação de bons costumes. As aulas eram em salas separadas e as meninas teriam uma mestra de primeiras letras e de gramática portuguesa para as que quisessem. Ensinava-se a coser, bordar, cortar roupas de senhoras e a costurar. Os meninos eram aceitos para morarem na mesma casa. $\mathrm{O}$ anúncio terminava destacando que havia mestres diferentes e tudo estava "estabelecido por ordem bem regulada". ${ }^{35}$ Assim, o ensino básico da alfabetização era facultativo às meninas.

Para além do ensino elementar, a Corte possibilitou também a criação de cursos superiores no Rio de Janeiro. Havia uma grande preocupação com a formação para a carreira militar, adequada a uma conjuntura de guerra - a das invasões francesas. De um lado, a Academia Real Militar, criada em 4 de dezembro de 1809, sob a inspiração de Rodrigo de Sousa Coutinho, que pretendia, em suas metas enquanto ministro de Estado dos Negócios Estrangeiros e da Guerra, prover o Império português de um exército profissional. De outro, a Academia dos Guardas-Marinhas, instituída em Lisboa em 1782, mas transferida de Portugal para o Rio de Janeiro, em 1808. D. Rodrigo, imbuído do caráter pragmático das luzes portuguesas, deseja dotar a Corte também com o ensino das ciências matemáticas, realizado nessas escolas, em busca de conhecimentos úteis que pudessem promover o progresso da nova sede do Império.

A Academia Real Militar, voltada à instrução dos oficiais do Exército, foi projetada ainda para ser a primeira instituição destinada a um curso completo das ciências matemáticas e de observação, além das ciências militares propriamente ditas (tática, fortificação, estratégia, castramentação, ataque e defesa de praças e artilharia). Era um espaço de formação científica, possibilitando um tipo de oficial formado por novas diretrizes pedagógico-científicas, resultantes de uma perspectiva prática. De certa forma, constituiu-se no único estabelecimento de ensino superior de engenharia no Brasil até 1874, quando foi criada a Escola Politécnica. ${ }^{36}$

35 Gazeta do Rio de Janeiro, n. 50, 24 de junho de 1815.

36 DUARTE, Elaine C. Academia Real Militar. In: VAINFAS, Ronaldo; NEVES, Lucia M. Bastos P. (Orgs,). Dicionário do Brasil Joanino..., p. 24-27. 
Inaugurada em 23 de abril de 1811, na Casa do Trem (hoje Museu Histórico Nacional), foi transferida no ano seguinte para o largo de São Francisco, em virtude dos exercícios práticos previstos em seus estatutos. Antes do início das aulas, um anúncio na Gazeta do Rio de Janeiro informava que estas se principiariam no $1^{\circ}$ ano com o curso de matemática. Aqueles interessados em se matricular deviam apresentar seus requerimentos, segundo as normas do decreto de criação, acompanhados de certidão de idade e da licença ou dispensa do serviço militar. ${ }^{37}$

Vários anúncios e notícias apareciam na Gazeta sobre a instituição acerca das aulas oferecidas, de professores e de nomes de alunos matriculados. Aliás, o próprio redator da Gazeta naquela época, Manuel Ferreira de Araújo Guimarães, era professor de matemática da instituição. Outro professor, conhecido por suas experiências físicas e químicas, em seu Laboratório químico, contando muitas vezes em suas conferências com a presença do príncipe regente ${ }^{38}$, era o Dr. Gardner, lente de química.

A outra instituição militar era a Academia Real dos Guardas-Marinhas, instalada nas dependências do mosteiro de São Bento, onde permaneceu até $1839 .{ }^{39}$ Iniciou suas atividades, oferecendo vagas ao público e matriculando também civis que queriam estudar matemáticas para exercerem outras atividades. Após o regresso de D. João para Portugal, em abril de 1821, a Academia continuou a funcionar normalmente, ainda que, em janeiro de 1822, seu diretor recebesse instruções de Lisboa para retornar junto com sua ampla e importante biblioteca. ${ }^{40}$

Quanto ao ensino médico, coube à Bahia a instalação da Escola de Cirurgia, em 1809, de acordo com proposta do cirurgião-mor do reino, José Maria Picanço. No Rio de Janeiro, em função da grande falta de médicos e cirurgiões, alguns expedientes foram estabelecidos até que fosse criada uma Academia Médico-Cirúrgica, em 1813. O príncipe regente, "em benefício da conservação e da saúde de seus vassalos", mandou estabelecer uma escola anatômica, cirúrgica e médica no Hospital Real Militar e da

Militar.

37 Gazeta do Rio de Janeiro, n. 28, 6 de abril de 1811.

38 Gazeta do Rio de Janeiro, n. 51, 26 de junho de 1811.

39 Funcionou no Largo de São Francisco, entre 1832 e 1833, quando incorporada à Academia

40 NEVES, Lucia M. Bastos P.; DUARTE, Elaine C. Academia dos Guardas-Marinhas. In: VAINFAS, Ronaldo; NEVES, Lucia M. Bastos P. (Orgs,). Dicionário do Brasil Joanino..., p. 22-24. Para os anúncios, ver Gazeta do Rio de Janeiro, n. 21, 13 de março de 1819 e n. 19, 4 de março de 1820. 
Marinha na Corte. Aproveitou alguns professores que já se encontravam no estabelecimento, como o médico da Câmara do príncipe regente, José Maria Bomtempo, para dar aulas de medicina clínica, elementos de matéria médica e de farmácia, a fim de permitir um maior aperfeiçoamento dos cirurgiões. ${ }^{41}$

Por fim, foi criada uma aula de Comércio, na Corte, em 1810, em função das novas atividades comerciais. Seguia o modelo daquela já existente em Lisboa, promovendo o conhecimento sobre escrituração mercantil, operações cambiais e línguas estrangeiras, que deviam ser ensinadas aos guarda-livros e caixeiros. Daí também o oferecimento, como visto, de aulas noturnas de língua francesa e inglesa para caixeiros por professores particulares. José Antonio Lisboa, um negociante de grosso trato, matriculado na Real Junta do Comércio de Lisboa desde 1801, foi escolhido para preencher o cargo. O curso tinha uma duração de três anos, mas, na visão de Maria Beatriz Nizza da Silva ${ }^{42}$, não foram muitos os que seguiram essa formação, pois caixeiros, guarda-livros e negociantes, em geral, aprendiam na prática e por meio de algumas obras publicadas para essa finalidade.

Verifica-se, portanto, que, a partir da vinda da Corte, diversas formas de instrução elementar e de ensino superior foram implementadas. Algumas conquistas foram realizadas, embora tal fato não signifique que a educação fora da escola ainda fosse uma prática comum entre as famílias mais abastadas. ${ }^{43}$ Da mesma maneira, para os mais humildes e os escravos, que se situavam nas fímbrias da sociedade, a transmissão de conhecimentos e o privilégio da escrita eram elementos desconhecidos pela maioria.

\section{Dos livros e seus atributos}

... le livre, cette forme la plus achevé du discours écrit, conquérait une formidable autorité.

Henri-Jean Martin ${ }^{44}$

\footnotetext{
41 Gazeta do Rio de Janeiro, n. 96, 12 de agosto de 1809.

42 SILVA, Maria Beatriz Nizza da. Gazeta do Rio de Janeiro..., p. 116.

43 Na França, dos séculos XVI a XVIII, prevaleceu esse modelo de educação. Cf. CHARTIER, R.; COMPÈRE, M. M.; JULIA, D. L'Éducation en France..., 1976, p. 293-297.

44 MARTIN, H.-J. Histoire et pouvoirs de l'écrit. Paris: Perrin, 1988. p. 283.
} 
Diversos anúncios de venda de livros para o aprendizado da arte da escrita multiplicaram-se a partir da publicação da Gazeta do Rio de Janeiro. Era o resultado da nova conjuntura que deu vida à cidade colonial. O comércio de livros, ainda que não desconhecido no início do oitocentos, ampliava suas possibilidades em função das mudanças acarretadas com a vinda da Corte. Livrarias já se encontravam ou eram instaladas. Requerimentos enviados à Real Mesa Censória, solicitando licença para despachar livros de Portugal, destinados a várias localidades brasileiras, como Rio de Janeiro, eram frequentes, sendo mencionados diversos negociantes franceses que atuavam em Lisboa. Igualmente, a partir de 1808, as licenças concedidas pela Mesa do Desembargo do Paço no Rio de Janeiro aos requerimentos feitos pelos livreiros para desembaraçar seus livros nas Alfândegas, os pareceres emitidos pelos censores régios e os próprios anúncios nos jornais confirmam que diversos livreiros atendiam a particulares e negociantes no Brasil. ${ }^{45}$ De outro lado, a Impressão Régia tornava-se também um aliado para a publicação de livros variados. Todo esse arcabouço constituía-se, portanto, em poderoso instrumento auxiliar da instrução e da transmissão do conhecimento, pois o livro investia-se de funções diversas, mas, sobretudo, as de educar e formar elites políticas, profissionais e intelectuais.

Nesse sentido, gramáticas, livros de leitura, de geografia e de história, das várias ciências - matemática, física, economia -, de direito e de medicina vinham à luz e passavam a ser anunciados. Instrução, leitura e livros tornavam-se elos de uma mesma cadeia - promover as luzes e atender as exigências da nova Corte, especialmente por se constituir em uma sociedade em que o escrito penetrava ainda parcialmente e os livros eram também raros e preciosos.

Tanto nas aulas régias quanto nos colégios, ensinar a escrever e a ler eram funções essenciais. Daí, a necessidade de gramáticas, especialmente da língua portuguesa. Como já anunciara Luís Antonio Verney, em seu Verdadeiro método de estudar, publicado em 1746, a "gramática é a porta dos outros estudos da qual depende a boa eleição dos demais" e é "a arte de falar e escrever corretamente" ${ }^{46} \mathrm{O}$ estudo da gramática era visto tanto

45 Cf. NEVES, Lucia Maria Bastos P. Impressores e livreiros: Brasil, Portugal e França, ideias, cultura e poder nos primeiros anos do oitocentos. Revista do Instituto Histórico e Geográfico Brasileiro, Rio de Janeiro, v. 173, p.277-313, out-dez. 2012.

46 VERNEY, L. A. Verdadeiro método de estudar. Edição organizada por António Salgado Júnior. Lisboa: Sá da Costa, 1949, v. I: Estudos Linguísticos, p. 26. 
numa perspectiva política e cultural, ao contribuir para ilustrar a nação e formar vassalos úteis à Coroa, quanto também em uma acepção prática, pois permitia a aprendizagem de outras línguas.

\begin{abstract}
Na loja da Gazeta se acham as seguintes Gramáticas da Língua Portuguesa: Arte da Gramática da Lingua Portuguesa, por Antônio José dos Reis Lobato, nova impressão de 1811, por 2\$000 réis - Arte da Gramática da Língua Portuguesa, por Figueiredo, por $1 \$ 280$ réis -, Epitome da Grammatica da Lingua Portuguesa, por Moraes, por $1 \$ 600$ réis - Gramática Filosófica da Língua Portuguesa comparada com a Latina para ambas se aprenderem ao mesmo tempo, por Jerônimo Soares Barbosa, por $2 \$ 000$ réis. $^{47}$
\end{abstract}

Neste anúncio de 1812, parte das gramáticas anunciadas foi escrita no século XVIII: a de Lobato, publicada em 1770, era considerada a primeira oficial, adotada nas escolas por ordem do Marquês de Pombal, mas sendo utilizada ao longo do século XIX; e a de Figueiredo (Pedro José de Figueiredo). As outras duas foram redigidas no início do oitocentos - a de Moraes (Antônio de Moraes Silva, 1806) e a de Jerônimo Soares Barbosa, escrita na fronteira entre os séculos XVIII e XIX, mas somente publicada pela Real Academia das Ciências de Lisboa em 1822, após seu falecimento. Este último destacava a importância de se estudar primeiro a língua portuguesa para depois se aprender com vantagem outras línguas, especialmente o latim. Ainda criticava as gramáticas portuguesas tradicionais, que reduziam seus estudos a um simples sistema informe e impreciso de exemplos e regras, fundamentados mais sobre analogias aparentes do que sobre a razão. Havia, portanto, uma crítica às gramáticas normativas, que tendiam a fundir todas na "mesma forma das gramáticas latinas". Propunha, então, uma gramática "raisonnée", filosófica, que hoje pode ser chamada de argumentativa. ${ }^{48}$ Dessa forma, a instrução elementar não conheceu a produ-

47 Gazeta do Rio de Janeiro, n. 5, 15 de janeiro de 1812.

48 BARBOSA, Jerônimo Soares. Grammatica Philosophica da Lingua Portugueza ou principios da Grammatica Geral aplicados á nossa linguagem. 2. ed. Lisboa: Typografia da Academia Real das Sciencias, 1830. p. X-XV. Cf. COELHO, Sónia. As ideias linguísticas nos Prólogos das gramáticas de Pedro José da Fonseca (1799) e de Jerónimo Soares Barbosa (1822). In: Anais do XXVI Encontro Nacional da Associação Portuguesa de Linguística, p. 171-173. Disponível em <http://www.apl.org.pt/docs/26-textos-seleccionados/Coelho.pdf>. Acesso em: 20/02/2014. 
ção de outras gramáticas da língua portuguesa, pois somente entre 1817 e 1819 Frei Caneca escrevia o Breve compendio de grammatica portuguesa, seguindo a perspectiva de uma gramática filosófica para elucidar a natureza da linguagem. Para o autor, a "Gramática portuguesa é a arte que ensina a falar, ler e escrever corretamente a língua portuguesa". ${ }^{9}$

Ressalte-se que há uma publicação da Impressão Régia de uma Gramática Latina moderna, redigida por Fr. Diogo de Mello Menezes, professor régio de língua latina em Lisboa. Tratava-se de uma reedição (edições portuguesas em 1795 e 1803), embora a gramática não tivesse encontrado grande recepção entre seus colegas de magistério. ${ }^{50}$

Se a gramática era vista como a essência para se aprender uma língua, nada mais natural que a Impressão Régia publicasse em 1820 uma gramática para o estudo da língua inglesa. Desde 1809, D. João oficializava o ensino de inglês no Brasil: primeiro, com a criação de uma cadeira na Real Academia Militar, cujo lente era Eduardo Thomaz Cohil, devendo, "enquanto se não abrirem as aulas da mesma Academia, principiar as suas lições no local" "1; segundo, com a decisão de criar uma cadeira de inglês e francês, apropriando-se do modelo de ensino ainda da época pombalina. De acordo com a decisão, os professores deviam:

ditar suas lições pela Gramática que fosse mais bem conceituada enquanto não formalizassem uma de sua composição, e habilitassem seus Discípulos na pronunciação das expressões, e das vozes das respectivas línguas, adestrando-os em bem falar e escrever, para o que deveriam servir-se dos melhores modelos do século de Luís XIV. [...] na escolha dos livros, seriam preferidos os de mais perfeita e exata moral, usando-se para comparação com a Língua Pátria os autores clássicos do século de quinhentos que melhor reputação tivessem entre os literatos. ${ }^{52}$

49 In: MELLO, Antonio Joaquim (Org.). Obras politicas e litterarias de Frei Joaquim do Amor Divino Caneca. Recife: Typographia Mercantil, [1875], p. 19. Considera-se a primeira gramática escrita por um brasileiro.

50 Novo Epitome de Grammatica Latina moderna ou verdadeiro methodo de ensinar latim a hum principiante. Rio de Janeiro: Impressão Régia, 1817. Para os comentários sobre a obra, ver CAMARGO, Ana Maria de A.; MORAES, Rubens Borba de. Bibliografia da Impressão Régia do Rio de Janeiro. v. I. São Paulo: EDUSP/Livraria Kosmos, 1993. p. 190.

51 Decreto de 30 de maio de 1809. BRASIL. Colleção das Leis do Brazil. v. 1. Rio de Janeiro: Imprensa Nacional, 1891.p. 67.

52 Decisão n. 29 de 14 de julho de 1809. BRASIL. Colleção das Leis do Brazil. v. 2, 1891. p. 28. 
Manoel José de Freitas, baiano, redigiu a primeira gramática, intitulada Compêndio da gramática inglesa e portuguesa para uso da mocidade adiantada nas primeiras letras. Em verdade, ela já havia sido editada pela primeira vez em Londres, em $1812 .{ }^{53} \mathrm{~A}$ importância do ensino do inglês em virtude das relações que foram estabelecidas entre a Corte portuguesa e a Grã-Bretanha ficava evidente em seu prólogo.

Animado pois por um coração liberal, resolvi preparar este Compêndio, considerando o tráfico e as relações comerciais da Nação Portuguesa com a Inglesa, e a falta de um Compêndio da Gramática de ambas, para iniciar e facilitar a Mocidade ao uso das suas Línguas, com a clareza, justeza e simplicidade possível; e penso que os pais de família, desejosos de melhor conhecimento, e, em parte, de mais civil e moral Educação para seus filhos, aprovaram este meu desígnio. ${ }^{54}$

O interesse pelo estudo da língua inglesa também era revelado no anúncio da Gazeta: "Na loja de Paulo Martin, [...] há de venda Spelling Books próprios para a mocidade aprender o idioma Inglês, seu preço 1600 réis". Trata-se, provavelmente, de A Pronouncing Spelling Book: with Select Lessons in Prose and Verse, de G. Fulton \& G. Knight, que, em 1813, se encontrava em sua $5^{\text {a }}$ edição. ${ }^{55}$ A curiosidade por obras e ideias inglesas ainda se confirmava naquela época com a tradução do original inglês por Bento da Silva Lisboa de Adam Smith-Compêndio da obra da Riqueza das Nações -, dedicada ao príncipe regente D. João, e feita de forma abreviada de modo a tornar "mais suave a sua leitura". ${ }^{56}$

Em relação à língua francesa, apesar de sua grande divulgação entre as elites letradas e do grande número de comerciantes e livreiros de origem

53 Nova grammatica portugueza e ingleza dedicada á felicidade e augmento da Nação Portugueza, publicado por G. F. Harris's Widow and Brothers, em Liverpool, no ano de 1812. A obra foi anunciada na Idade d'Ouro do Brazil, n. 30, 13 de abril de 1813, estando à venda na loja da Gazeta na Bahia. Cf. MAGALHÃES, Pablo Antonio Iglesias. A palavra e o Império: Manoel de Freitas Brazileiro e a nova Gramática inglesa e portuguesa. Clio. Revista de Pesquisa Histórica, João Pessoa, v. 1, n. 31, 2013. Disponível em: <http:/www.revista.ufpe.br/ revistaclio/index.php/revista/article/view/283>. Acesso em: $18 / 02 / 2014$.

54 FREITAS, Manuel José de. Compendio da grammatica inglesa e protugueza. Para uso da mocidade adiantada nas primeiras letras. Rio de Janeiro: Impressão Régia, 1820. p. 1.

55 Para a indicação da obra em inglês, cf. Edinburg: Peter Hill, 1813. Para o anúncio, Gazeta do Rio de Janeiro, n. 43, 29 de maio de 1813.

56 Rio de Janeiro: Impressão Régia, 1811, s.n. Os tomos 2 e 3 foram publicados em 1812. 
francesa, não se encontrou nenhuma publicação de gramática ou de ensino da língua na Tipografia Régia. Tal fato não impedia o grande número de obras que chegavam ao Rio de Janeiro para serem despachadas nas Alfândegas por meio de licenças no Desembargo do Paço, sendo anunciadas com frequência na Gazeta. Além das obras de Belas Letras, havia muitas de caráter científico e técnico, além de diversos dicionários, entre outros - dicionários de francês e português e português-francês; dicionário francês-alemão; dicionário espanhol-francês e francês-espanhol. ${ }^{57}$ Outros livros eram indicados para o ensino do francês. Um indivíduo, que havia estudado há alguns anos na França, oferecia um curso de seis meses, com lição de uma hora e meia por dia. O estudante só precisava "de um Telêmaco e um dicionário de francês para principiar". Prometia que, no final de seis meses, o estudante sensato e tendo trabalhado seria capaz de "verter, escrever e falar o francês". Curioso é que a obra escolhida era Les aventures de Télémaque, de Fénelon, que foi grande sucesso de vendas nos séculos XVIII e XIX..$^{58}$ Outro professor - P. A. Ribis - optava por um novo método de ensino: o de M. Dufief, autor de um Dicionário e Gramática francesa nos Estados Unidos. ${ }^{59}$

Demonstrando a disponibilidade de livros franceses, cabe mencionar o anúncio de M. Izidor, professor de língua francesa, que dispunha de "uma biblioteca de livros franceses muito bem escolhidos", que se podiam ver das 3 horas às 5 horas da tarde. Além dos estudos da língua francesa, oferecia também os de geografia e dava lições particulares. Em 1819, anunciava que abria o seu segundo curso de língua francesa. ${ }^{60}$

Para o ensino da leitura, eram escassos os livros destinados a esta atividade para uso da mocidade luso-brasileira. O primeiro livro publicado para crianças na América joanina na Impressão Régia foi Leitura para meninos, que continha uma coleção de histórias morais relativas aos defeitos ordinários às idades mais novas e um diálogo sobre a geografia, cronologia, história de Portugal e história natural. A iniciativa coube a José Saturnino da Costa Pereira, a quem se atribui a sua organização. A obra foi anunciada

57 Cf. Gazeta do Rio de Janeiro, n. 32, 18 de abril de 1812 e n. 93, 19 de novembro de 1816.

58 Gazeta do Rio de Janeiro, n. 98, 2 de dezembro de 1815.

59 Gazeta do Rio de Janeiro, n. 50, 21 de junho de 1817. Em fevereiro de 1829, o London Magazine ainda comentava e anunciava o método de M. Dufief. Disponível em $><$ books.google.com.br/ books?id=5vARAAAAYAAJ $>$. Acesso em: 23/02/2014.

60 Jornal de Annuncios, n. 4, 26 de maio de 1821. Para a última informação, ver Gazeta do Rio de Janeiro, n. 86, 27 de outubro de 1819. 
na Gazeta em 1818 e ganhou novas edições em 1821, 1822 e 1824. Esse sucesso pode ser explicado por se ter encontrado um novo público de alunos que aprendiam a ler. Além disso, constituía-se como um verdadeiro manual de civilidade. ${ }^{61}$ Há notícias também de outro livro didático intitulado Tesouro dos meninos, de autoria de Pierre Blanchard, que foi traduzido do francês por Mateus José da Rocha. ${ }^{62}$ Outra obra no gênero, anunciada pela Gazeta, era Escola nova cristã e política, de D. Leonor Tomásia de Sousa e Silva, pseudônimo de Francisco Luís Ameno. Publicado em Lisboa em 1799, o livro tinha como objetivo ensinar os primeiros rudimentos a um menino cristão, dando-lhe as regras gerais para em pouco tempo aprender a ler, escrever e contar, além de princípios de geografia. ${ }^{63}$

A necessidade de obras neste gênero, apesar de não serem impressas pela Tipografia Régia, aparecia nos catálogos dos livreiros. Entre os livros vendidos por Manoel Antonio da Silva Serva, com lojas na Bahia e no Rio de Janeiro, encontravam-se Alfabetos com princípios de Doutrina Cristã, Alfabeto para a instrução da mocidade, Coleção de cartas para meninos, Instrução literária, Elementos de sintaxe e Gramática portuguesa, entre outros. ${ }^{64} \mathrm{O}$ negociante francês Pierre Constant Dalbin, que chegou ao Brasil em 1816, também publicou em 1820 um catálogo das obras que vendia em sua casa. Em sua relação, que comportava cerca de 170 livros escritos em português, francês, espanhol, latim e grego, havia livros de gramática e literatura, podendo-se encontrar até mesmo um dicionário de chinês, francês e latim. ${ }^{65}$

As obras de cunho propriamente histórico não foram abundantes no período, uma vez que se utilizavam, sobretudo, de textos de História de

61 CAMARGO, Ana Maria de A.; MORAES, Rubens Borba de. Bibliografia da Impressão Régia..., p. 202.

62 Cf. SILVA, Maria Beatriz Nizza da. Cultura e sociedade no Rio de Janeiro (1808-1821). São Paulo: Companhia Editora Nacional, 1977. Ver ainda: ZILBERMAN, Regina. No começo a leitura. Em aberto, Brasília, v. 16, n. 69, jan./mar.1996. p. 16.

63 Gazeta do Rio de Janeiro, n. 100, 15 de dezembro de 1819. Para o esclarecimento do nome do autor, ver SEVERINO, Isa Margarida Vitória. A escola nova cristã e política de Francisco Luís Ameno: edição e estudo de aspectos linguísticos e pedagógico-didáticos. Dissertação (Mestrado em Linguística) - Universidade de Aveiro, 2005. Escola nova christã e politica... escripta para uso de seus filhos. Lisboa: Officina de Joaquim de Thomas Aquino Bulhoens, 1799.

64 Notícia do catálogo de livros de Manoel da Silva Serva. Rio de Janeiro: Impressão Régia, 1811.

65 Catálogo de livros portugueses que se achão de venda em casa de P. Dalbin \& Cia. Rio de Janeiro, [Typographia Régia], 1820. 
Portugal. Na Impressão Régia, destaca-se a História do Brasil, de Alphonse Beauchamp, traduzida pelo Padre Inácio Felizardo Fortes. Tratava-se, no fundo, de uma obra inspirada naquela de Roberto Southey, considerado pela historiografia como o autor da primeira história geral do Brasil, abrangendo desde o período colonial até a chegada de D. João. Publicada em três volumes, em inglês, veio à luz entre 1810 e 1819. É curioso ressaltar que Beauchamp, apesar de ser acusado de plagiar Southey, teve seu texto traduzido, no Brasil, em 1818, muito antes daquele de seu "inspirador", que só foi vertido para o português em 1862. Beauchamp afirmava que nenhuma história geral e completa do Brasil havia aparecido, nem em francês, nem em outra alguma língua da Europa, só havendo viagens e fragmentos históricos e não um corpo de história. ${ }^{66}$ É digna ainda de menção a Corografia Brasílica, escrita pelo padre Manoel Aires de Casal. A obra fora anunciada na Gazeta do Rio de Janeiro em 1815, com apelo aos subscritores que deveriam depositar "por cada exemplar 1:600 réis". Tratava-se, na visão do periódico, de uma "obra útil" e desejada, pois expunha a "divisão, extensão e limites das Províncias"; a descrição do estado atual de cada uma delas, indicando ali o que havia de notável. Narrava ainda a época e o método de sua colonização, precedida da História desde seu descobrimento em 1500 até 1532, quando o Brasil foi repartido em Capitanias. ${ }^{67}$ A obra, no entanto, só foi publicada em 1817.

Ainda foram publicadas diversas memórias históricas, como as de José da Silva Lisboa, Memórias da vida de Lord Wellington (1815) e Memória dos benefícios políticos do governo de D. João VI (1818), sendo que esta última foi considerada a primeira obra, apesar de seu caráter extremamente laudatório, a trazer à tona alguns dos aspectos mais importantes do período joanino. ${ }^{68}$ Outras memórias foram publicadas, mas não consistiam propriamente em livros para o ensino da história. Vinham à luz para um público erudito e constituíam apenas um arcabouço para a escrita de uma história, uma vez que eram isentas de qualquer tipo de interpretação e possuíam um objetivo claramente definido - memorar todos os fatos que lhe pareceriam dignos de construírem uma futura história que ilustrasse e

66 Alphonse de Beauchamp. Historia do Brasil desde a sua descuberta até 1810... Tradução do francês pelo padre Ignacio Felizardo Fortes. Rio de Janeiro, Impressão Régia, 1818-1819.

67 Gazeta do Rio de Janeiro, n. 59, 26 de julho de 1815.

68 Cf. CAMARGO, Ana Maria de A.; MORAES, Rubens Borba de. Bibliografia da Impressão Régia... v. 1, p. 203. 
imortalizasse algum grande personagem. Os anúncios de jornais e catálogos publicizavam, sobretudo, livros referentes a Histórias de Portugal, até mesmo sobre o Ultramar e as Histórias sagradas. Assim, Paulo Martin, o livreiro mais importante do período joanino, anunciava na Gazeta uma obra publicada, em 1818, pela Academia das Ciências de Lisboa, intitulada História e Geografia das Nações Ultramarinas, que vivem nos domínios Ultramarinos ou a elas são vizinhas. ${ }^{69}$

Já os estudos de geografia tornavam-se essenciais, uma vez que se relacionavam ao comércio, à agricultura, à marinha e à arte militar. Tais obras interessavam aos cursos superiores e eram, quase sempre, escritas em francês. A Gazeta anunciava Dicionário geográfico em francês, a Geografia Moderna de Meunier, ou a Geographia moderna de Portugal e Hespanha, ornada de varias passagens d'Historia Natural, Politica e Commerciante destes dous reinos, com o mapa de Portugal. Ainda despertava curiosidade a obra intitulada Mappa Geografico Historico \& do Reino de Portugal, iluminado em quatro mapas, "que mostram em um só golpe de vista o mais essencial da Geografia, da História e da Monarquia Portuguesa". ${ }^{70}$

Da mesma forma, a inauguração de uma aula de comércio, no Rio de Janeiro, possibilitou a publicação e anúncios de livros referentes a esta atividade, bem como à economia política.

Na loja da Gazeta se acha a interessantíssima obra: $O$ guarda livros moderno ou curso completo de instrucções sobre as operações do Commercio tanto em Mercadorias como em Banco, 2 vol. [...]. O tomo $2^{\circ}$ que trata do método de escriturar livros do Negociante por Partidas dobradas conforme o estilo mais usado nos principais Escritórios mercantis da Europa, se vende separadamente [...]. Tratado de cambios util e necessarios aos estudantes da Real Aula do Commercio [...]. ${ }^{71}$

O primeiro livro, publicado em Lisboa em 1816, de autoria de Manuel Teixeira Cabral de Mendonça, era dedicado aos negociantes portugueses, e o último veio à luz na mesma data, sem autor declarado.

69 O nome correto da obra é Collecção de noticias para a Historia e Geografia das nações ultramarinas que vivem nos domínios portugueses, ou lhes são visinhas, escrita por diversos autores.

70 Gazeta do Rio de Janeiro, n. 39, 17 de maio de 1815 e n. 36, 3 de maio de 1817. Para o último livro ver n. 87, 30 de outubro de 1816 .

71 Gazeta do Rio de Janeiro, n. 87, 30 de outubro de 1816. 
A importância da matéria era grande, naquela época em que o Brasil abria-se para o comércio internacional, pois este era considerado a base firme dos interesses políticos e o equilíbrio das nações, resultando no bem comum de toda a sociedade. Tanto que se ofereciam livros à "mocidade de comerciantes que não pode frequentar as aulas de [comércio]", como Instrucções de arithmetica.$^{72}$

Em relação à ciência econômica, destacam-se os inúmeros trabalhos publicados por José da Silva Lisboa pela Impressão Régia. Inspirado nas ideias ilustradas e nos escritos de Adam Smith, Lisboa era um letrado conhecedor das teorias econômicas estrangeiras e, por meio de seus escritos, procurava demonstrar o melhor meio de promover a riqueza da nação, louvando as últimas medidas do governo joanino. Desde Observações sobre o comércio franco no Brasil (1808-9) a Estudos do bem comum e economia politica, ou ciência das leis naturais e civis de animar e dirigir a geral indústria e promover a riqueza nacional, e prosperidade do Estado (1819-20), Silva Lisboa buscava propagar tal ideário na América Joanina. Como já citado, não se pode esquecer que seu filho - Bento da Silva Lisboa - traduziu parte da obra de Adam Smith.

Ainda em relação aos estudos superiores, diversas obras vieram à luz sobre a arte militar, pois tornava-se necessária a impressão de manuais, voltados para diversas matérias, tais como física, matemática e química. Eram livros adotados na Real Academia Militar, publicados pela Impressão Régia e traduzidos, em sua maioria, do francês. Entre os livros de matemática, podem-se citar: Elementos d'álgebra, de Leonardo Euler, para uso dos alunos da Academia Militar; Elementos de geometria, por Adrien Marie Legendre; Tratado de trigonometria, do mesmo autor; Tratado elementar de aritmética, por Sylvestre F. Lacroix; Elementos de geometria descritiva, para uso da Academia Militar e Variações dos triângulos esféricos. As obras foram traduzidas pelos próprios lentes da Academia: Manuel Ferreira de Araújo Guimarães cuidava dos títulos de matemática; José Saturnino da Costa Pereira, dos estudos de mecânica; e José Vitorino dos Santos e Souza, das obras de álgebra. O primeiro livro publicado pela Impressão Régia foi Elementos de Geometria, em 1809, por ordem do príncipe regente. A obra foi impressa pela primeira vez em Paris, no ano de 1794, e se tornou

72 Gazeta do Rio de Janeiro, n. 48, 17 de junho de 1818. 
clássica na linha desses estudos. Traduzida por Araújo Guimarães, apresentava 13 estampas com figuras geométricas, as primeiras a serem gravadas na Impressão Régia. Foi anunciada na Gazeta do Rio de Janeiro em 18 de outubro de $1809 .{ }^{73}$ Os anúncios informavam, em sua maioria, que a publicação destinava-se aos alunos da Academia Militar:

Saíram à luz: Elementos d'Algebra de Leonardo Euler, por ordem de S.A.R., o Príncipe Regente Nosso Senhor, postos em linguagem para o uso dos Alunos da Academia Militar desta Corte, Tomo $1^{\circ}$, da Analyse determinada. Vendem-se nas casas de Paulo Martin, filho, na rua da Quitanda; e de Manoel Jorge, na rua do Rosário, a1\$600 réis. ${ }^{74}$

É curioso destacar que as traduções desses livros científicos circularam também do outro lado do Atlântico: um catálogo que saiu à luz em Lisboa, em 1812, informava que obras publicadas pela Impressão Régia no Rio de Janeiro encontravam-se à venda na loja de Paulo Martin e Filhos. Entre estas, destacavam-se livros técnico-científicos, especialmente as traduções de textos de matemática e geometria, impressos para a utilização na Academia Real Militar do Rio de Janeiro. ${ }^{75}$

O papel da Impressão Régia foi igualmente importante na divulgação de obras para atender à demanda criada pela Escola Anatômica, Cirúrgica e Médica no Rio de Janeiro. Esta foi instrumento fundamental para a legitimação do campo médico e de sua prática, possibilitando a formação de elites profissionais que contribuíram, por meio do conhecimento adquirido, para a melhoria das condições de saúde da população e para cumprir um papel social visando a melhoramentos da saúde pública. Maria Beatriz Nizza da Silva afirma que, naquele contexto, a Medicina seria "a

73 Cf. CAMARGO, Ana Maria; MORAES, Rubens Borba de. Bibliografia da Impressão Régia do Rio de Janeiro... v. 1, p. 21. Para uma análise das obras científicas da Impressão Régia, ver OLIVEIRA, José Carlos de. D. João VI: o adorador do Deus das Ciências. A constituição da cultura científica no Brasil (1808-1821). Rio de Janeiro: E-papers, 2005, e GARCIA, Lucia Maria Cruz. Dos prelos da Impressão Régia, a cultura científica do período Joanino (1808-1821). Tese (Doutorado) - Programa de História da Universidade do Estado do Rio de Janeiro, 2011, especialmente, capítulo 4.

74 Gazeta do Rio de Janeiro, n. 33, 24 de abril de 1811.

75 Catálogo das obras impressas no Rio de Janeiro e que se acham à venda em Lisboa na loja de... Paulo Martin e Filhos. Lisboa: Oficina da Viúva Neves e Filhos, 1812. Havia também livros de medicina. 
mais 'social' de todas as ciências, isto é, aquela que mais se imbrica na vida cotidiana de uma sociedade". ${ }^{76}$

Assim, encontram-se trabalhos destinados às aulas, como Tratado de inflamação, e ulceras extrahido da Nosographia cirúrgica, de Anthelmo Richerand, traduzido pelo médico da cadeira de Medicina Operatória e cirurgião da Armada Real Joaquim da Rocha Mazarem, que ainda possibilitou a publicação de outros trabalhos de autores estrangeiros, como Xavier Bichat (Indações Physiologicas sobre a Vida e a Morte) ${ }^{77}$. Também os trabalhos do médico francês Phillipe Pinel foram difundidos por meio das traduções de José Maria Bomtempo, professor da Academia e médico da Câmara de Sua Alteza Real. Ele organizou ainda os Compendios de materia medica feitos por Ordem de Sua Alteza Real. ${ }^{78} \mathrm{O}$ livro destinava-se, especialmente, aos alunos da Academia, conforme se lê na "Prefação" da referida obra:

Obedecer ao Soberano e ser útil ao Público, eis o objeto da presente Obra.

Quando o Príncipe Regente Nosso Senhor, por seu Real Decreto de 12 de abril de 1809, criou a Cadeira de Matéria Médica, ordenou que ela fosse dirigida para complemento do curso cirúrgico já estabelecido; [...]

Determinou, pois, Sua Alteza Real, que eu arranjasse desde logo um resumo literário, relativo a este objeto, para servir às lições da dita Cadeira própria a explicar semelhantes matérias. [...] Era a verdade grande o objeto para as minhas forças, grande para alunos que não possuíam conhecimentos de Química, e História Natural, e muito maior para a brevidade com que me ordenou formar o presente trabalho, que já se achava organizado em setembro de $1810 .^{79}$

Sem dúvida, houve também uma preocupação da Coroa com livros voltados para a saúde pública - em especial, a questão do saneamento da capital do Reino. Por exemplo, Reflexões sobre alguns dos meios por

76 SILVA, Maria Beatriz Nizza da. Cultura e sociedade no Rio de Janeiro (1808-1821). São Paulo: Editora Nacional, 1978. p. 126.

77 Gazeta do Rio de Janeiro, n. 5, 15 de janeiro de 1812.

78 Publicado no Rio de Janeiro, na Regia Officina Typographica, no ano de 1814.

79 BOMTEMPO, José Maria. Compendios de materia medica feitos por Ordem de Sua Alteza Real. Rio de Janeiro: Regia Officina Typographica, 1814. Prefação, p. V-VIII. 
mais conducentes para melhorar o clima da cidade do Rio de Janeiro, de autoria do físico-mor do Reino e médico da Real Câmara Manoel Vieira da Silva. Esta obra foi a primeira, editada pela Impressão Régia, em 1808, cuja temática voltava-se para a saúde pública.

Verifica-se, por conseguinte, que a oferta de textos impressos relativos ao conhecimento e ao saber ampliou-se, de forma significativa, nas primeiras duas décadas do oitocentos, em consonância com o estímulo que a Coroa propiciava em relação à instrução e ao ensino. Acompanhavam o ritmo dos movimentos da nova capital do Império português, indicando a sua importância para aqueles que detinham o privilégio do saber e da escrita em uma sociedade onde o letramento ainda era raro e representava um ornamento que os distinguia de outros segmentos sociais.

Em 1808, o Rio de Janeiro ganhava novos ares: a Corte, com a presença do rei, atraía grande número de pessoas vindas de outras partes do Brasil, de Portugal e de outros países da Europa, como a Inglaterra e a França. Para desempenhar essa posição no interior do Império português, o Rio conheceu profundas mudanças que davam roupagens inéditas à velha cidade colonial. Mas, sobretudo, precisava de novidades no que dizia respeito à instrução e às práticas de leitura propiciadas pela circulação de livros e ideias. Nesse cenário, não se encontrava ausente um projeto das elites luso-brasileiras em constituir uma sociedade culta e ilustrada.

Assim, de um lado, a instrução conheceu uma diversidade em suas modalidades para propiciar educação elementar e superior não apenas aos filhos daqueles que se transferiram com a Corte para o Brasil, como também aos das elites mercantis e culturais que aqui se faziam presentes e pretendiam galgar novos espaços nesta sociedade de Corte. Além disso, como era evidente, a instrução atendia ainda às necessidades burocráticas da Coroa. Pela leitura dos anúncios de jornais, verifica-se que este público se formava a partir do ensino local, fornecido pelas aulas régias, seminários, colégios, academias militares ou adquiriam uma cultura de autodidatas, feita de leituras erráticas e fragmentárias. Os mais afortunados partiam para a Universidade de Coimbra.

De outro, era preciso também fornecer instrumentos para que essa instrução se tornasse viável. O início da tipografia no Brasil permitiu a publicação de livros que, junto com uma abertura do comércio, ampliou 
em muito as possibilidades de leitura daqueles que procuravam uma melhor instrução. Mesmo para a mocidade que apenas desejava aprender a ler, contar e escrever, alguns textos escritos eram imprescindíveis. Dessa forma, pode-se estabelecer uma correlação entre o ensino e a publicação de obras que lhe eram destinadas ${ }^{80}$ Era a possibilidade, na visão da época, de "difundir as luzes pelo povo", por edições de obras úteis e de se cumprir a pedagogia da civilização. Da leitura de bons livros dependiam os negócios da vida. Afinal, acreditava-se que conhecimento era poder ${ }^{81}$, especialmente em uma sociedade em que poucos detinham o privilégio do saber e da escrita. $\mathrm{O}$ escrito paulatinamente impunha-se na Corte e em cidades mais importantes. Isto não impedia, porém, que outras formas de transmissão do conhecimento características do Antigo Regime ${ }^{82}$ continuassem em vigor, especialmente a tradição ou a imitação de gestos no seio da comunidade familiar. A formação fora da escola permanecia a regra geral no Brasil do início do oitocentos.

De qualquer forma, a civilização começou a se fazer representar por meio dessas novas e rarefeitas elites. Herdeiras das Luzes, elas não podiam deixar de considerar a educação o instrumento fundamental para difundir a civilização e o progresso. Na realidade, por oposição ao mundo litúrgico do Antigo Regime, de que tinham a pretensão de afastar-se, acreditavam que a modernidade definia-se pela capacidade dos homens de intervir na realidade, modificando-a pelo uso da razão e o conhecimento objetivo dos fatos ${ }^{83}$ Por conseguinte, não bastava reger a ordem estabelecida, mas cumpria criar as condições para a sua transformação. Transformação que, ao romper com a tradição, exigia a implantação de mecanismos capazes de incutir os novos valores - ou seja, de instruir. Instruir mais do que educar, porque o rumo estava traçado e definido pelo conhecimento esclarecido de que essas elites se julgavam as portadoras.

Recebido em março de 2014. Aprovado em abril de 2014.

80 Afinal, como afirma Georges Duby, a história consiste no estabelecimento de correlações. DUBY, Georges; LARDREAU, Guy. Dialogues. Paris: Flammarion, 1980. p. 101.

81 LISBOA, José da Silva. Observações sobre a prosperidade do Estado..., p. 79-80.

82 Cf. CHARTIER, R., COMPÈRE, M. M.; JULIA, D. L'Éducation en ..., p. 292.

83 FURET, F.; OZOUF, J. François Furet \& Jacques Ozouf, "Trois siècles de métissage culturel". In: Lire et écrire. v. 1, Paris: Minuit, 1977. p. 349-369. 